\title{
AOR
}

Selected Papers of \#AolR2018:

The $19^{\text {th }}$ Annual Conference of the

Association of Internet Researchers

Montréal, Canada / 10-13 October 2018

\section{CITIZEN OR CONSUMER? THE RIGHT TO DATA ACCESS IN THE EUROPEAN UNION AND AUSTRALIA}

James Meese

University of Technology Sydney

\section{Introduction}

This paper examines what data is made available for people to access on social media platforms, analyses the practicalities and potential uses of this data and compares the key differences between conceptualising data access as a consumer right versus a fundamental right of digital citizenship (McCosker et al., 2016; Daly, 2016). It features early stage findings from a research project that explores whether the provision of data access addresses concerns that have emerged with regards to data collection by private and public actors and the analytic possibilities engendered by "Big Data" (see boyd and Crawford, 2012).

\section{Literature Review}

I take the European Union's General Data Protection Regulation (GDPR) (Regulation 2016/679) as a point of departure. Citizens within the boundaries of the European Union recently secured the right to data access under this framework. Chapter 3, Article 15 (1) states that "[t]he data subject shall have the right to obtain from the controller [...] access to the personal data". The right works in conjunction with Article 20, which provides a right to data portability, meaning that consumers can request their data in "a structured, commonly used and machine-readable format", like an Excel .CSV file. These rights apply to any organisation that collects data and so apply equally to airlines, pizza shops, cloud services and social media platforms (Vanberg and Ünver, 2017). At first glance, the benefits of this right are apparent. While organisations collect vast amounts of data from consumers, this data is often held at one remove from individuals (Tene and Polonetsky, 2012). Subsequently, a right to data access stands as one way of reversing the otherwise unidirectional process of data extraction that typifies contemporary life.

Suggested Citation (APA): Meese, J. (2018, October 10-13). Citizen or Consumer? The Right to Data Access in the European Union and Australia. Paper presented at AolR 2018: The $19^{\text {th }}$ Annual Conference of the Association of Internet Researchers. Montréal, Canada: AolR. Retrieved from http://spir.aoir.org. 
However, some privacy scholars have critiqued the increased focus on data access rights. While Daniel Solove (2013, p. 1893) generally supports data access, he questions the extent to which people can "self-manage" their privacy and argues that for a variety of reasons, "privacy self-management impedes its ability to achieve its goal of giving people meaningful control over their data". More directly, Helen Nissenbaum (2017) critiques Omer Tene and Jules Polonetsky (2012) (amongst others) and contends that data collection needs to be regulated with interventionist policies, suggesting that a data access right will not solve the fundamental issues surrounding extensive data production and collection.

\section{Methods and Contribution}

This paper makes two interventions in the above debate. Firstly, it analyses the extent to which data access and portability addresses some of these foundational concerns around privacy by examining how social media companies have responded to the incoming GDPR regulations. I outline what levels of access social media platforms provide and assess the portability of the data provided through detailed case studies of Twitter and Facebook. This involves an analysis of each platform's current data access policies and processes, an examination of what sort of data is made available as well as a brief historical account of how data access has been treated on both platforms. Findings will reveal whether Twitter and Facebook's current data access regimes are comprehensive and operate as the basis of a functional privacy management strategy.

Secondly, it offers a conceptual intervention through a comparative analysis of the divergent approaches two jurisdictions take to data access. I compare the GDPR with an ongoing debate around the introduction of a consumer data access right into Australian law. Whereas European Union treats privacy law "as a fundamental right anchored in interests of dignity, personality, and self-determination" (Schwartz and Peifer 2017, p. 123), Australia has a comparatively weak privacy law (Lindsay, 2005) and as a result is treating the emerging issue of data access as a consumer rights issue. This paper will assess how these divergent legal foundations and public discourses alter the conceptualisation and enacting of the data access right (and digital rights more generally).

\section{Conclusion}

This paper provides a timely examination of a right that has emerged in response to the increased datafication of society (see boyd and Crawford, 2012). As well as offering a detailed analysis of how social media platforms have responded to the data access provisions within the GDPR, the comparative analysis of the EU and Australia shows that significantly different legal foundations can animate this right, ultimately presenting two starkly different visions of internet users as either consumers or citizens. The paper suggests that despite its limitations, the EU right provides enough agency to "data subjects" to be of use to citizens in other jurisdictions. As a result, the paper contends that consumer-oriented approaches to digital rights are likely to be flawed and need to be challenged in favour of a substantive vision of digital citizenship. The competing trajectories of the data access right underline the fact that this tension between viewing 
people as either consumers or citizens is still ongoing and has a real impact on prospective law reform efforts.

The project also speaks to the growing recognition of data's materiality (Coté, 2014). Organisations, governments and most critically, everyday people no longer view digital data as "a wholly immaterial phenomenon" (Lupton 2017, p. 1603). The emergence of the data access right shows that individuals expect personal data to be something that can be made material, accessed and handled with relative ease. As a result, governments increasingly have to legislate with reference to data's materiality. This study of the data access right offers an account of how legal frameworks and corporate policies have started to (sometimes reluctantly) recognize the materiality of data.

\section{References}

boyd, d. and Crawford, K 2012, 'Critical questions for big data: Provocations for a cultural, technological, and scholarly phenomenon', Information, Communication \& Society, vol. 15, no. 5, pp. 662 - 679.

Coté, M 2014, 'Data motility: The materiality of big social data', Cultural Studies Review, vol. 20 , no. 1, p.121 - 149 .

Daly, A 2016, Private power, online information flows and EU law: Mind the gap, Bloomsbury Publishing, London.

Lindsay, D 2005, 'An exploration of the conceptual basis of privacy and the implications for the future of Australian privacy law', Melbourne University Law Review, vol. 29, no. 1, pp. $131-178$.

Lupton, D, 2017, 'Feeling your data: Touch and making sense of personal digital data', New Media \& Society, vol. 19, no. 10, pp.1599-1614.

McCosker, A, Vivienne, S and Johns, A (eds.) 2016, Negotiating digital citizenship: Control, contest and culture, Rowman \& Littlefield International, London.

Nissenbaum, H 2017, 'Deregulating Collection: Must Privacy Give Way to Use Regulation?', viewed 12 February 2018, Available at SSRN:

https://ssrn.com/abstract=3092282.

Schwartz, P and Peifer, K 2017, 'Transatlantic Data Privacy Law', The Georgetown Law Journal, vol. 106, no. 1, pp. $115-179$.

Solove, D 2012, 'Introduction: Privacy self-management and the consent dilemma'. Harvard Law Review, vol. 126, no. 7, pp.1880 - 1903.

Tene, $\mathrm{O}$ and Polonetsky, J 2012, 'Big data for all: Privacy and user control in the age of analytics', Northwestern Journal of Technology and Intellectual Property, vol. 11, no. 5, pp. $240-273$. 
Vanberg, A and Ünver, M 2017, 'The right to data portability in the GDPR and EU competition law: odd couple or dynamic duo?', European Journal of Law and

Technology, vol. 8, no. 1, viewed 12 February 2018, http://ejlt.org/article/view/546/726. 